\title{
O uso de técnicas de nucleação na restauração de áreas degradadas no Polo Centro Norte-APTA, Pindorama-SP e no IMES-Catanduva-SP
}

\author{
The use of nucleation techniques in the restoration of degraded areas in the Polo \\ Centro Norte-APTA, Pindorama-SP and in IMES-Catanduva-SP, Brazil
}

\author{
Angela Cristina Bieras ${ }^{1}$, Tamiris Marion de Souza ${ }^{2}$, Maria Teresa Vilela Nogueira Abdo ${ }^{3}$, Romulo Sensuline Valaretto ${ }^{4}$
} Antonio Lucio Mello Martins ${ }^{5}$

\begin{abstract}
Resumo: Nucleação é capacidade que algumas espécies têm de induzir a restauração ambiental por meio de técnicas nucleadoras oferecendo abrigo, alimentação e reprodução acelerando assim o processo sucessional e diversidade local. Para promover a restauração ambiental no Polo Centro Norte- APTA e do IMES- Catanduva, foram selecionadas três áreas degradas adjacentes à fragmentos florestais: cultura agrícola (1), pastagem (2) e área desprovida de vegetação (3), instalando em cada área diferentes técnicas nucleadoras: 4 poleiros artificiais, 4 núcleos de galharia, 8 plantio de mudas em grupo Anderson, banco de sementes do solo e chuva de sementes. Após 15 meses a área de pastagem (2), por ter proximidade com fragmento florestal rico em diversidade e sem invasoras apresentou melhor resultado. $\mathrm{Na}$ área sem vegetação (3), teve aumento lento de biodiversidade devido à proximidade a fragmentos pobres em diversidade. Na área agrícola (1), com presença de invasoras, apenas alguns núcleos tiveram sucesso como o plantio de mudas em grupo de "Anderson" e chuva ou banco de sementes germinadas em viveiro e mudas transplantadas após rustificação. Poleiro artificial, galharia e banco ou chuva de sementes direto no solo, não são recomendados, pois devido a mato-competição, as plântulas germinadas são abafadas e provavelmente não sobrevivem.
\end{abstract}

Palavras-chaves: Biodiversidade, poleiros artificiais, galharia, chuva de sementes.

Abstract: Nucleation is the environmental restoration by several techniques that provides shelter, food and breeding accelerating the succession process and diversity. In order to promote environmental restoration in the Polo Centro NorteAPTA and in the IMES-Catanduva-SP, Brazil, three degraded areas next to forest remnants were selected: agriculture (1), pasture (2) and area without vegetation (3) where nucleation techniques were deployed in each area 4 artificial pershes, 4 brushwood, 8 planting seedlings in Anderson group, soil seed bank and seed rain. After 15 months the results showed that: the pasture area (2) located beside forest remnant with high diversity and without weeds had better results. Nucleation technique is limited and promotes slow biodiversity increase when located close to remnants with low diversity as in the area without vegetation (3). In agricultural area (1), with weeds, the nucleation technique was also limited, being successful in only a few nuclei as the planting of seedlings in the "Anderson Group" and rain or seeds banks pre-germinated in nursery and seedlings transplanted after hardening. Artificial perch, brushwood and bank or direct seed rain on the ground, are not recommended, once due to weed competition, the germinated seedlings will be muted and probably not survive.

Key words: Biodiversity, artificial perches, brushwood, seed rain

\footnotetext{
*Autor para correspondência

Recebido para publicação em 14/05/2015; aprovado em 10/09/2015

${ }^{1}$ Doutorado em Ciências Biológicas (Biologia Vegetal) pela Universidade Estadual Paulista Júlio de Mesquita Filho, campus de Rio Claro. Docente curso de Agronomia, UNIRP. E-mail: acbieras@gmail.com

${ }^{2}$ Graduação em Licenciatura Plena e Bacharelado em Ciências Biológicas pela Faculdade de Filosofia Ciências e Letras de Catanduva - IMES. E-mail: tamirismdsouza@hotmail.com

${ }^{3}$ Doutorado pela UNESP, Campus de Jaboticabal, e em Produção vegetal e Pesquisadora Científica nível III da APTA, Agencia Paulista de Tecnologia dos Agronegócios, com auação no Pólo APTA Centro Norte, Pindorama -SP. E-mail: mtvilela@ terra.com.br

${ }^{4}$ Graduação em Licenciatura Plena em Ciências Biológicas pelo Instituto Municipal de Ensino Superior de Catanduva. E-mail: corvoretto@ hotmail.com

${ }^{5}$ Doutorado pela Escola Universidade Estadual Paulista Júlio de Mesquita Filho, UNESP, FCAV, Jaboticabal SP. E-mail: 1martins@apta.sp.gov.br
} 


\section{INTRODUÇÃO}

A restauração de áreas degradadas representa uma atividade básica para a conservação in situ refazendo comunidades e formando corredores entre fragmentos vegetacionais (REIS et al, 2003).

Diferentes modelos de restauração adotados ao longo dos tempos foram concebidos a partir de algumas visões e concepções distintas dos processos ecológicos. Inicialmente desenvolveu-se um modelo extremamente produtivista, com aspectos predominantemente quantitativos e objetivando a produção da biomassa vegetal. A visão dendrológica foi reforçada pela incorporação da fase arbórea, pulando todas as demais fases iniciais da sucessão. Onde é dada importância a estrutura da floresta em detrimento dos processos dinâmicos naturais. Um modelo posterior avançou para uma visão de conservação, primando por valorizar a diversidade vegetal. A diversidade foi vista como uma meta a ser alcançada em curto prazo através do uso de modelos quantitativos e de caráter estrutural da floresta, onde a riqueza e densidade foram os dois parâmetros fundamentais a serem mensurados. Uma nova tendência prima por modelos de conservação da biodiversidade para a conservação da biofuncionalidade e resgate de interações entre organismos do sistema. Esta visão não se baseia em modelos determinísticos, mas na possibilidade de aumentar as probabilidades da sucessão se expressar e de abrir espaço para os fenômenos eventuais (REIS et al, 2006).

A capacidade de uma espécie em propiciar uma melhoria nas qualidades ambientais, permitindo aumento da probabilidade de ocupação deste ambiente por outras espécies é conhecida como nucleação onde espécies componentes de uma comunidade, após a sua implantação e posterior morte permitem que outros organismos mais exigentes possam colonizá-la (REIS et al, 2003b). Esse processo se instala com o aumento do ritmo de colonização, a partir de uma espécie promotora que tem a capacidade de propiciar uma significativa melhoria nas qualidades ambientais, permitindo a ocupação deste ambiente por outras espécies.

A nucleação é um princípio sucessional na colonização natural de áreas em formação (REIS et al, 2003) e seu efeito pode ser mais facilmente notado em ecossistemas de vegetação aberta, onde há menor densidade de plantas e maior entrada de luz, resultando num clímax edáfico.

A restauração por meio de nucleação é caracterizada por diversas técnicas que são implantadas, nunca em área total, mas sempre em núcleos, a fim de deixar espaços abertos para o eventual se expressar, ocupando em média 5\% da área. Cada uma das técnicas nucleadoras de restauração possui diversos efeitos funcionais e particularidades que, em conjunto, produzem uma variedade de fluxos naturais sobre o ambiente degradado, mantendo processos-chave e contribuindo para resgatar a complexidade de condições dos sistemas naturais (REIS et al, 2006).

As atividades de restauração, baseadas no processo ecológico de nucleação, foram denominadas por REISet al. (2003) de "técnicas nucleadoras de restauração". São consideradas como técnicas nucleadoras: a) formação de coberturas de solo resultante de semeadura direta de espécies herbáceo-arbustivas, preferencialmente nativas ou exóticas anuais (milheto e girassol) para atração precoce de fauna, recuperação de solo e contenção de gramíneas exóticas invasoras; b) formação de abrigos artificiais, através do enleiramento de galharia, para alimentação e abrigo de consumidores e decompositores (desencadeamento de cadeias tróficas), além da restituição de solo; c) transposição mensal de chuva de sementes, para introdução de plantas regionais que frutificam em todos os meses do ano (manutenção de fauna) e de todas as formas de vida, visando promover fluxo gênico com as populações dos fragmentos mais próximos; d)transposição de solo para restituição do banco de sementes e biota do solo; e) poleiros artificiais para atração de avifauna e quiropterofauna; e f) plantio de mudas de espécies arbóreas em grupos de Anderson, formando núcleos adensados para eliminação de gramíneas exóticas invasoras e facilitar a regeneração de espécies nativas.

As técnicas nucleadoras de restauração formam microhabitats em núcleos onde são oferecidas, para as diferentes formas de vida e nichos ecológicos, condições de abrigo, alimentação e reprodução, que num processo de aceleração sucessional irradiam diversidade por toda a área. Dessa forma, a natureza poderá se manifestar da melhor forma possível dentro das condições da paisagem trabalhada (BECHARA, 2006).

Trabalhos que possam contribuir com dados e relatos de áreas que foram restauradas empregando as técnicas e princípios de nucleação são de grande utilidade.

Dentro desta necessidade objetivou-se testar a restauração ambiental em três situações de campo distintas (área com cultura agrícola (1), área com pastagens (2) localizadas no Polo Centro Norte- APTA, no município de Pindorama-SP e área completamente desprovida de vegetação (3) localizada no município de Catanduva-SP, distantes entre si $12 \mathrm{~km}$, empregando-se as seguintes técnicas nucleadoras: poleiro artificial, enleiramento de galharia, plantio de mudas em grupo Anderson,banco de sementes do solo e chuva de sementes.

\section{MATERIAL E MÉTODOS}

\section{Descrição das áreas de estudo.}

Os estudos tiveram início em fevereiro de 2011 e foram realizados em três áreas distintas: duas áreas (1 e 2) localizadas no Polo Centro Norte-APTA, no município de Pindorama-SP, e a área 3, localizada no campus do Instituto Municipal de Ensino Superior (IMES), no município de Catanduva-SP (Figura 1). Sendo que Área 1 - antigo plantio de café; Área 2 - pastagem e Área 3 - área completamente desprovida de vegetação.

A área 1 foi explorada com a cultura de café por aproximadamente 40 anos e, com a retirada desta cultura a cerca de três anos, a terra foi deixada em pousio. A área 2 é considerada "área pousio", ocupada por pastagem por cerca de 10 anos e sem receber nenhum tratamento de solo durante este período. Ambas as áreas possuem aproximadamente $3.600 \mathrm{~m} 2$. 
O uso de técnicas de nucleação na restauração de áreas degradadas no Polo Centro Norte-APTA, Pindorama-SP e no IMESCatanduva-SP

Figura 1. Demarcação e coordenadas de áreas 1 e 2 no Polo Centro Norte em Pindorama-SP e área 3 no IMES , em Catanduva-SP

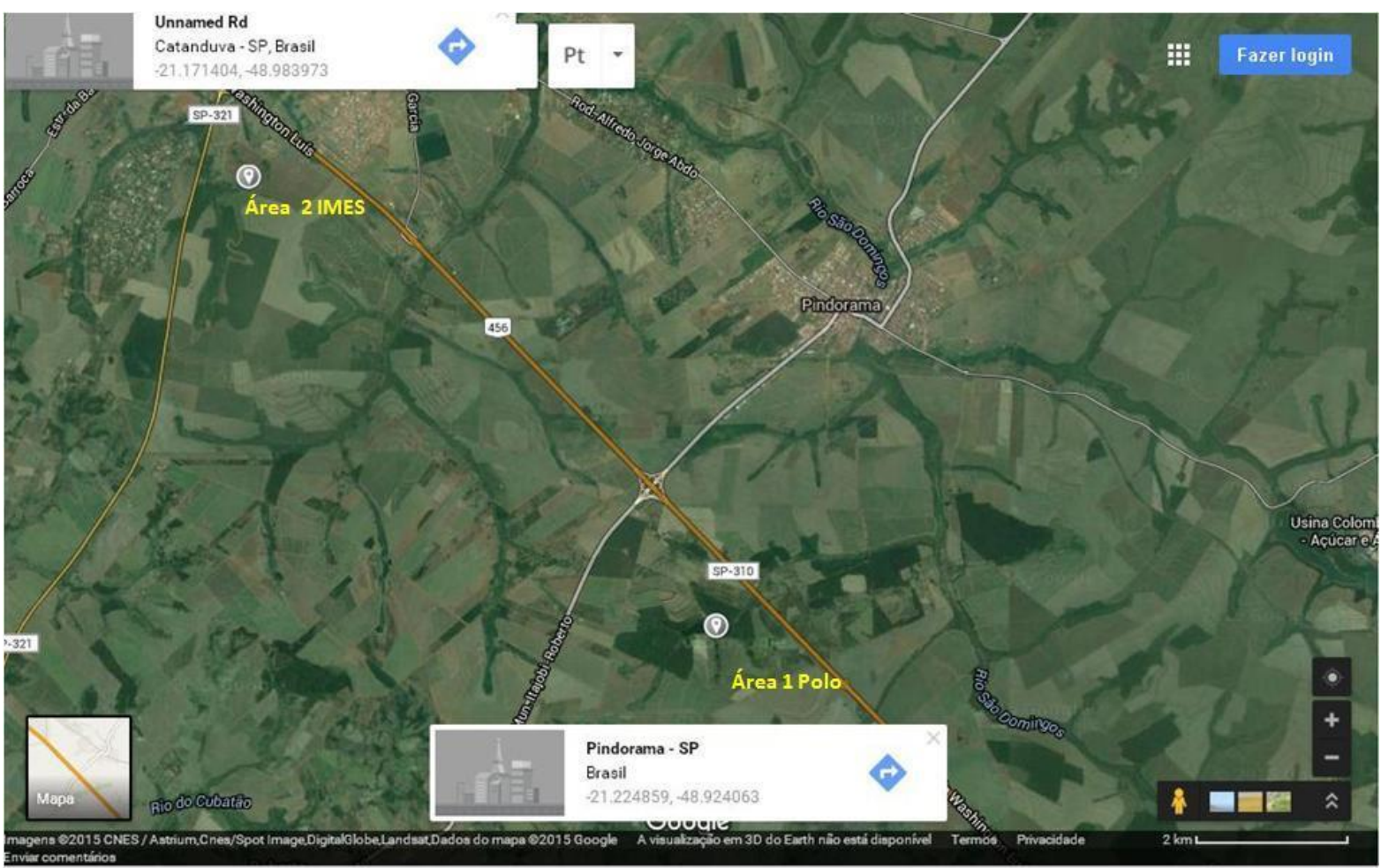

A área 3 pertence ao campus do Instituto Municipal de Ensino Superior de Catanduva e situa-se na Rodovia Washington Luis - SP 310 - Km 382, sendo completamente desprovida de vegetação, da qual foi retirado solo para uso em obras civis. Esta área possui $3.600 \mathrm{~m} 2$, e situa-se ao lado de um reflorestamento com espécies florestais nativas. As três áreas estudadas estão divididas em quatro parcelas de $900 \mathrm{~m}^{2}(15$ x $60 \mathrm{~m})$, aproximadamente. Dentro de cada parcela foram instalados núcleos de biodiversidade, de maneira aleatória.

\section{Preparo preliminar das áreas de estudo}

As áreas de estudo foram georreferenciadas com o uso de GPS (Fig. 2). A área total foi calculada e os croquis elaborados se encontram ilustrados pelas figuras 3 e 4 . Em cada local de estudo, foram retiradas amostras de solo compostas (Fig. 2), na profundidade de 0 a $10 \mathrm{~cm}$, para caracterização da fertilidade.

Figura 2. Demarcação de áreas (A-B) e coleta de solo para análise da fertilidade (C-E)

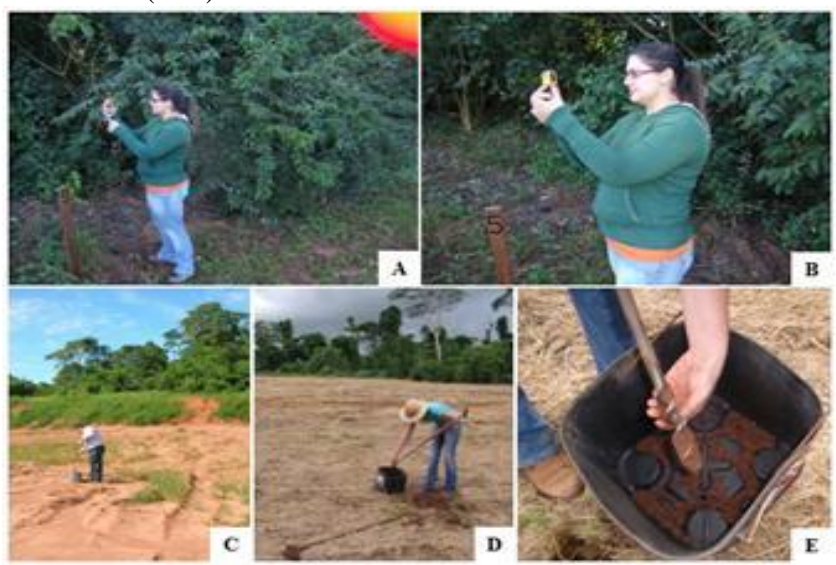

Figura 3. Vista geral do Polo e proximidade aos remanescentes florestais matas com alta diversidade (A-B) demarcação área 1 (C) e área 2 (D).

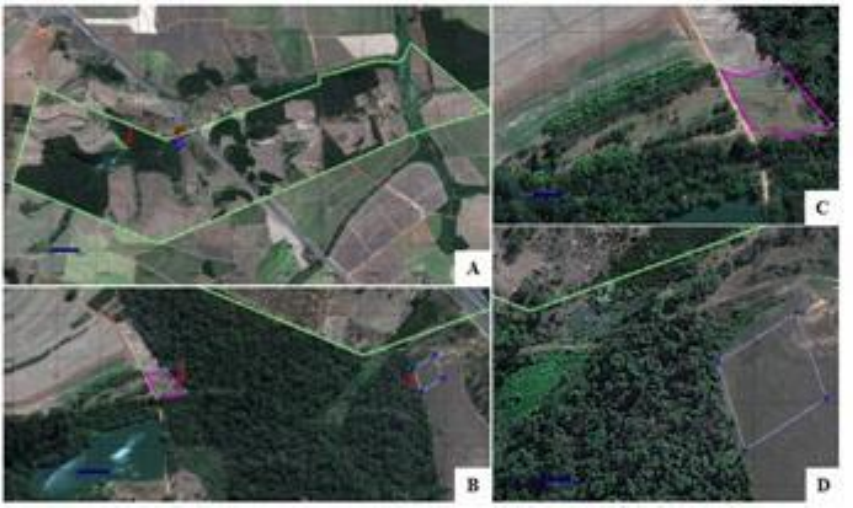

Figura 4. Área 3 (A e B) próxima a fragmento de mata resultante de reflorestamento com pobre em diversidade.

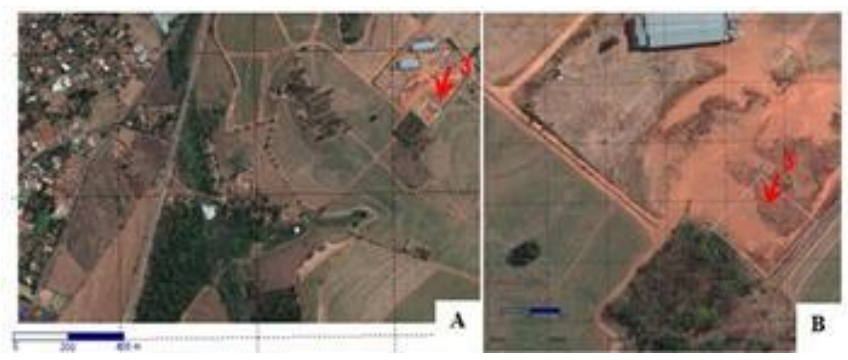

Com o objetivo de preparar o local para a retirada do banco de sementes do solo, foram abertas picadas, nas matas próximas aos locais de estudo, conforme ilustrado pela figura 5 . 
Figura 5. Abertura de picadas na mata e preparo do local para a retirada do banco de sementes do solo.

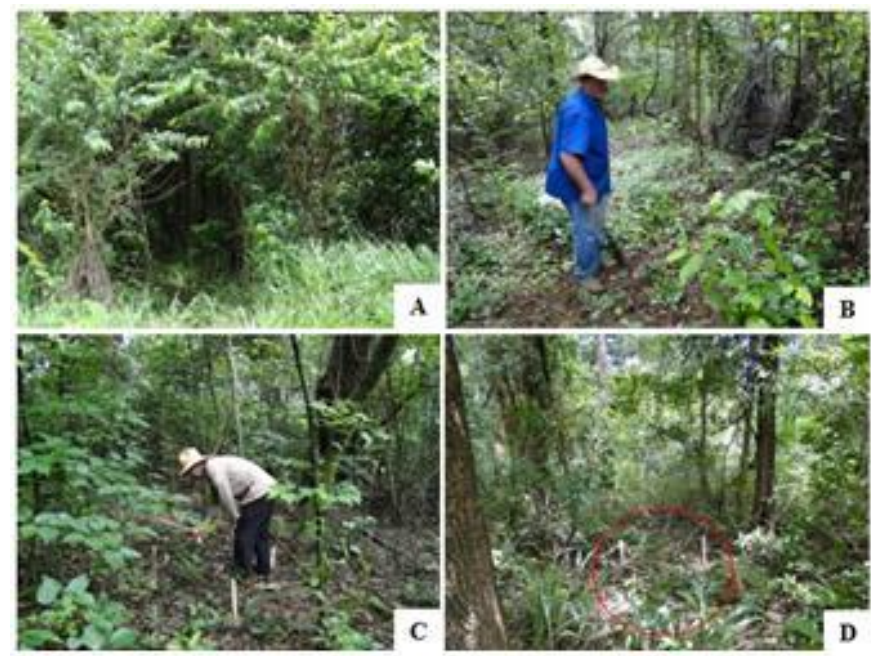

\section{Confecção de poleiros artificiais}

Em cada área de estudo, foram confeccionados diretamente no local quatro poleiros artificiais (Fig. 6), utilizando-se três varas de bambu, de aproximadamente $5 \mathrm{~m}$ de altura, deixando-se galhos e folhas no topo e meio dos poleiros para aumentar a área para pouso das aves.

Figura 6. Confecção de poleiros artificiais.

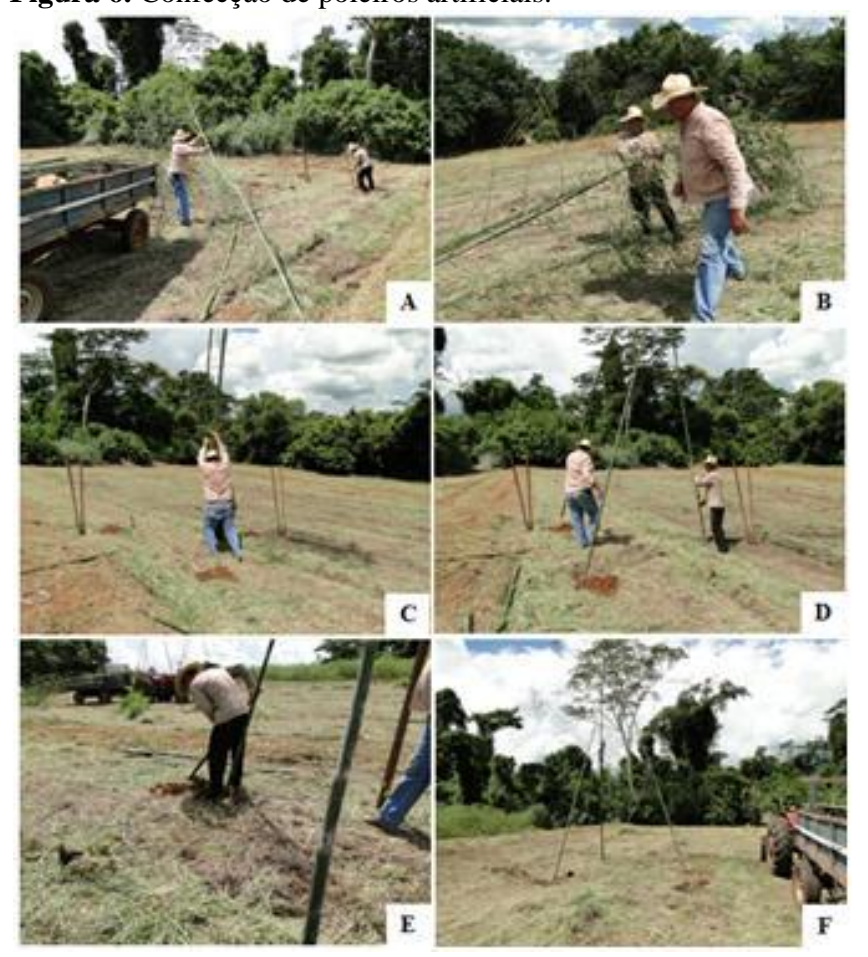

\section{Confecção de núcleos de galharia}

Os núcleos de galharia foram confeccionados utilizando restos de podas de árvores. Tomou-se o cuidado de não colocar material reprodutivo no local, para que não tenha o risco de contaminação, no caso do uso de espécies exóticas. Para todas as áreas de estudo, foram confeccionados quatro núcleos de galharia, de aproximadamente $1 \mathrm{~m}$ de altura, com extensões que variam em torno de $1,5 \mathrm{~m}$, conforme ilustrado pela figura 7 abaixo.

Figura 7. Confecção de núcleos de galharia.
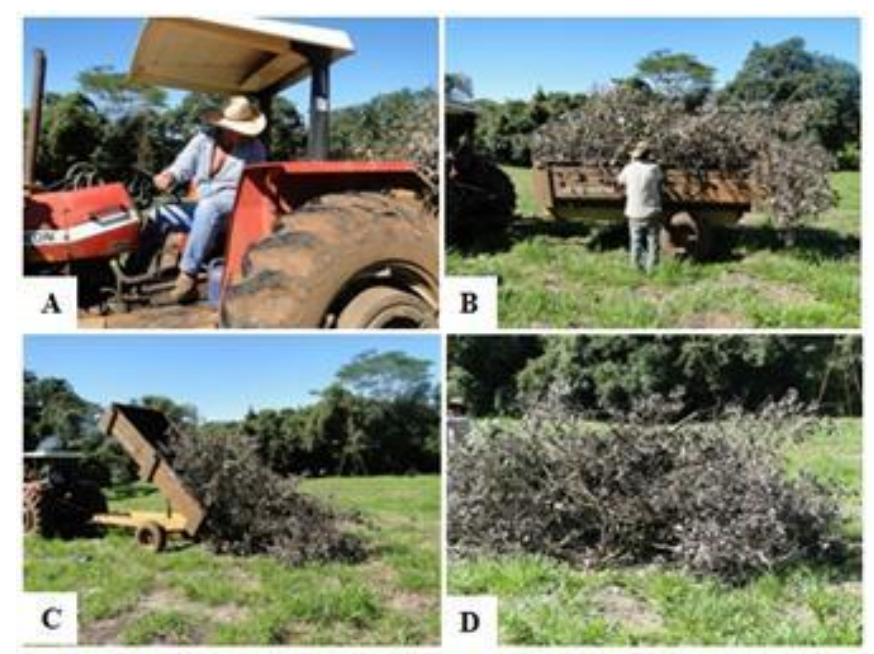

\section{Plantio de mudas em Grupo de Anderson}

Em cada local de estudo, foram instalados oito grupos de mudas (Fig. 8), seguindo o esquema "Grupo de Anderson". Segundo este esquema, as mudas são plantadas em grupo de cinco (em forma de cruz Fig. $11 \mathrm{~F}$ ), sendo uma espécie clímax no centro e quatro pioneiras ou secundárias iniciais na periferia. $\mathrm{O}$ objetivo deste esquema de plantio é o crescimento rápido das mudas e, por estar bem adensadas, o rápido sombreamento do local em questão, tornando-se este um núcleo propício para o desenvolvimento de outras espécies vegetais, provenientes tanto do banco de semente do solo local, quanto trazidas por animais que venham ali se abrigar. As espécies escolhidas para o plantio são todas nativas e pertencentes à flora regional.

Antes do plantio, as covas foram adubadas com superfosfato simples (0-18-0), na dose de $250 \mathrm{~g}$ de adubo por cova. Devido às características climáticas dos locais e ao tipo de solo, foram escolhidas espécies xerófitas, ou seja, capazes de se desenvolver com pouca exigência de água no solo.

O nome das espécies e o grupo ecológico aos quais elas pertencem podem vistos na Tabela 1.

Tabela 1. Listagem dos nomes científicos e vulgares das espécies usadas no plantio do Grupo de Anderson e grupos sucessionais a que pertencem Confecção de poleiros artificiais

\begin{tabular}{llll}
\hline \multicolumn{4}{c}{ Espécies plantadas nos Grupo de Anderson } \\
\hline Grupo Sucessional & Nome Científico & Nome Vulgar & Família \\
\hline Pioneira & Parapiptadenia rigida & Angico amarelo & Fabaceae \\
Pioneira & Parkia multijuga & Faveira pé de arara & Fabaceae \\
Pioneira & Guazuma crinita & Algodão do mato & Sterculiaceae \\
Secundária Inicial & Jacaranda cuspidifolia & Jacarandá mimoso & Bignoniaceae \\
Climácicas & Swietenia macrophylla- & mogno & Meliaceae \\
\hline
\end{tabular}


Estas espécies se encontram ilustradas pela figura 8.

Figura 8. Espécies nativas plantadas nas três áreas: Swietenia macrophylla- mogno (A), Parapiptadenia rigida- angico amarelo (B), Parkia multijuga- faveira pé de arara(C), Guazuma crinitaalgodão do mato(D) e Jacaranda cuspidifolia- jacarandá mimoso (E).

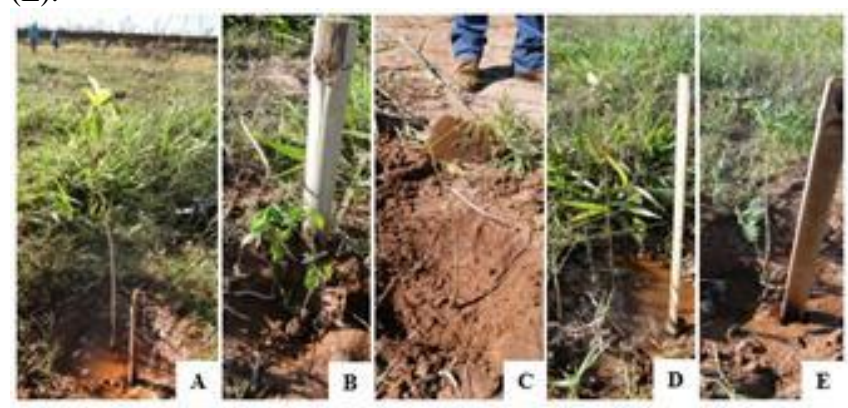

Coleta e preparo no viveiro, da chuva de sementes.

Os processos de dispersão de sementes propiciam a manutenção da diversidade genética das populações. Áreas degradadas têm sua capacidade de dispersão de sementes perdida ou diminuída. Nesta técnica são instalados em áreas florestais próximas a áreas degradadas coletores de chuva de sementes que captarão parte da chuva nesses locais. O material coletado pode ir para canteiros de semeadura indireta (sementeiras) ou ser semeado diretamente no campo, onde formará pequenos núcleos com folhas e sementes.

Para a coleta da chuva de sementes, foram utilizados coletores distribuídos ao acaso no interior dos fragmentos de mata do Polo Centro Norte-APTA (Fig. 9 A). A chuva de sementes foi levada para o viveiro da unidade (Fig. 9 B-F), visando a germinação e o estabelecimento das mudas, para posterior plantio nas áreas de estudo, após estarem rustificadas.

Figura 9. $\mathrm{A}=$ coletor de chuva de sementes; $\mathrm{B}-\mathrm{F}=$ preparo $\mathrm{e}$ condução, em viveiro, da chuva de sementes.

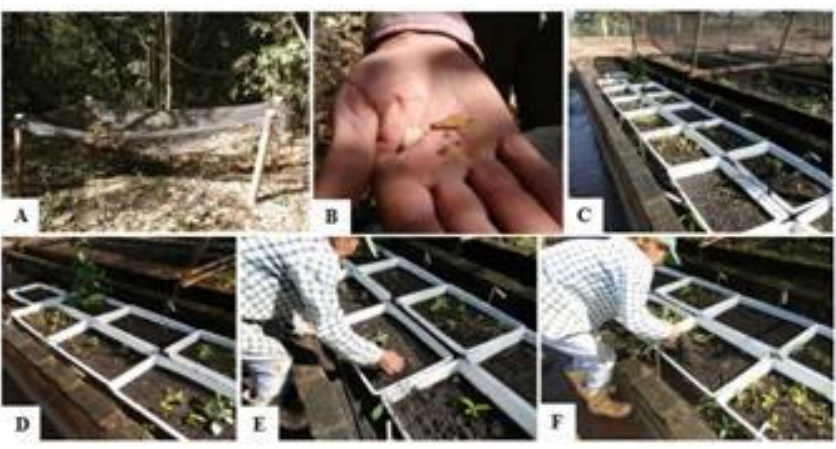

Coleta e preparo no viveiro, do banco de sementes do solo.

Em áreas anteriormente marcadas, no interior dos fragmentos de mata próximos a cada um dos locais de estudo, são retiradas amostras de solo com serrapilheira, numa profundidade de aproximadamente $10 \mathrm{~cm}$ (Fig. 9 A-B). Este material foi levado para o viveiro do Polo Centro Norte, foi colocado em bandejas, utilizando-se uma camada de areia sobre e sob o mesmo, com o objetivo de manter a umidade por mais tempo (Fig. $9 \mathrm{C}-\mathrm{H}$ ). Após o estabelecimento e a rustificação das plantas, o material das bandejas foi transplantado para os locais de estudo (áreas 1, 2, e 3).

Figura 10. Coleta e preparo no viveiro, do banco de sementes do solo.

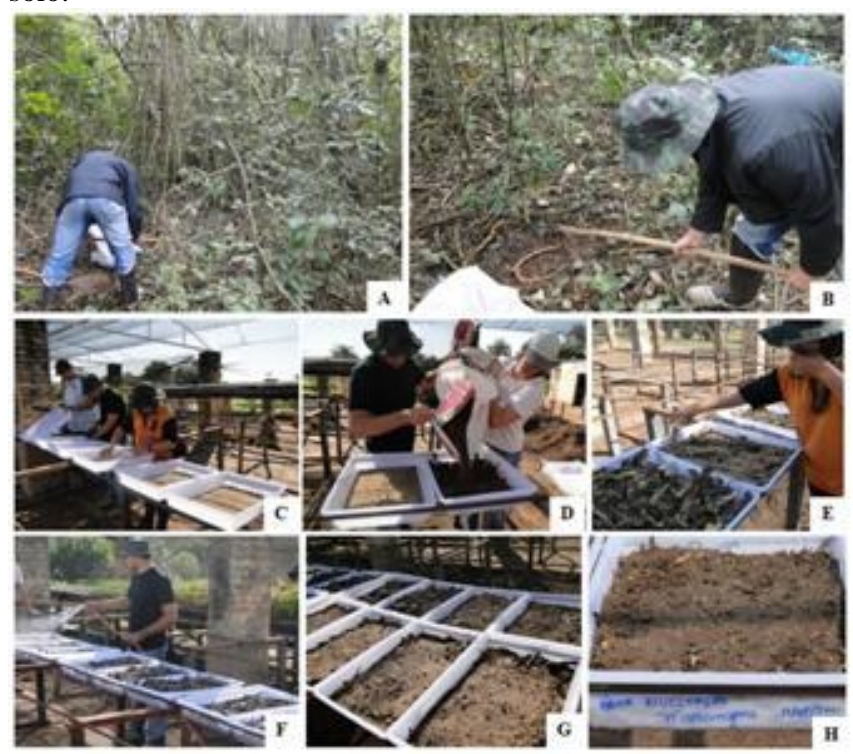

Instalação das áreas de estudo.

Em todas as áreas de estudo, foram instalados: 4 poleiros artificiais, 4 núcleos de galharias e 8 grupos de Anderson, conforme ilustrado pelas figuras 11 a 14 .

Figura 11. Instalação da área $1 . A-B=$ galharias. $C-D=$ confecção de poleiros artificiais. E-F = plantio de mudas em "grupo de Anderson".
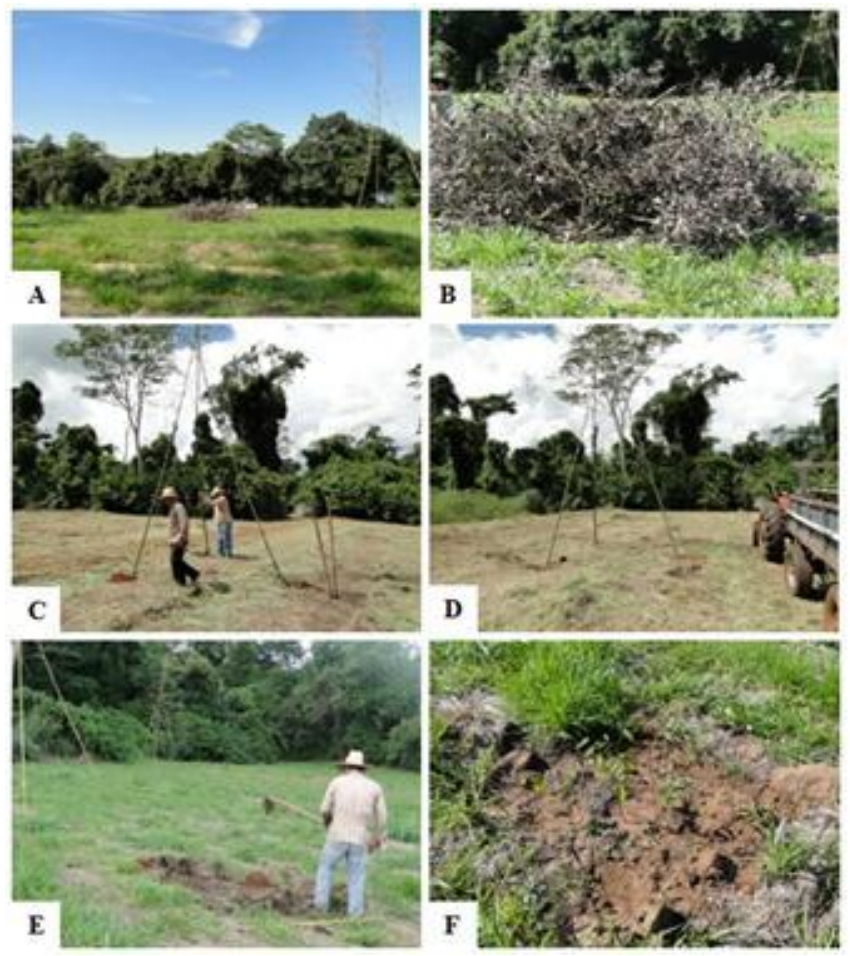
Figura 12. Instalação da área $2 . \mathrm{A}-\mathrm{B}=$ galharias. $\mathrm{C}=$ plantio de mudas em "grupo de Anderson". D = presença de formigas no local, as quais foram controladas com a aplicação de inseticida. $\mathrm{F}=$ regas periódicas.

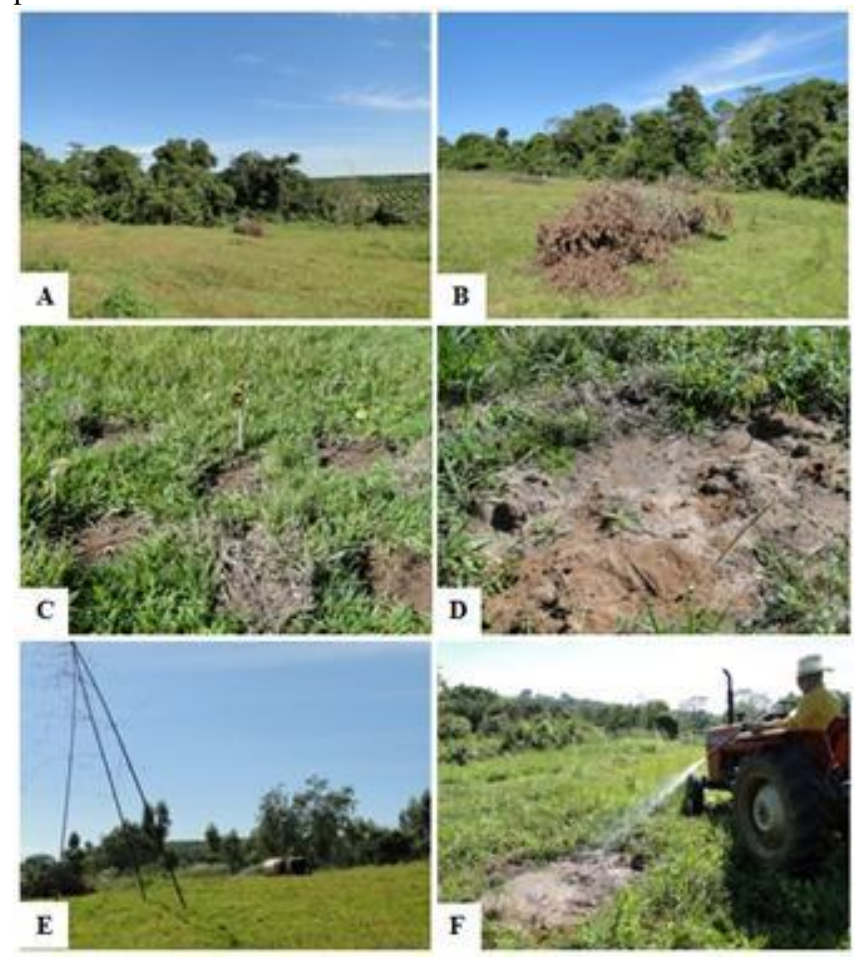

Figura 13. Instalação da área 3. Vista geral da área, com poleiros (setas amarelas) e galharias instalados.
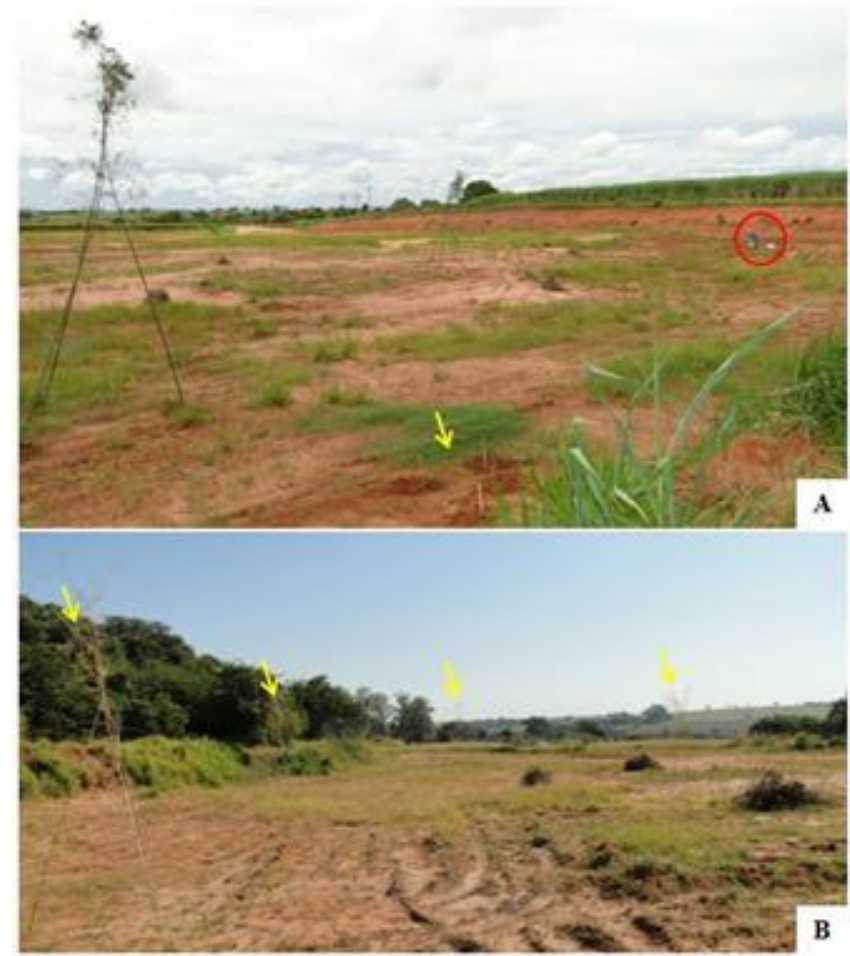

Figura 14. Plantio de mudas na área 3; realizado por alunos e docente do IMES Catanduva e por funcionários do Polo Centro Norte.

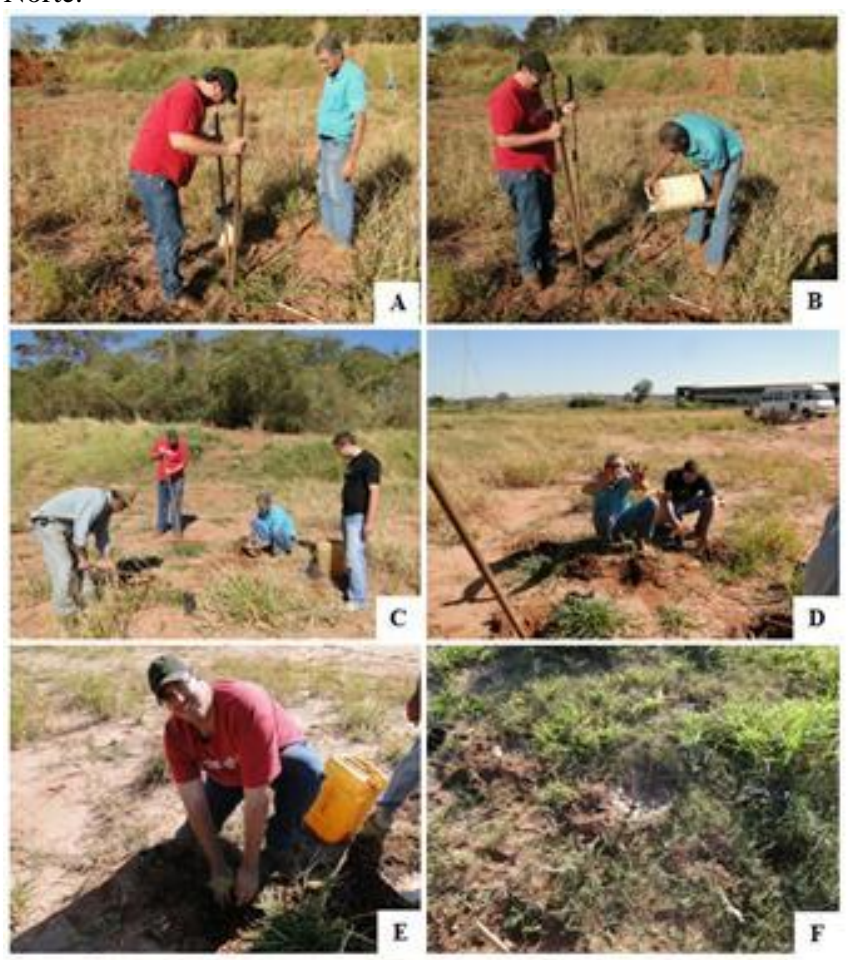

\section{RESULTADOS}

\section{Avaliação após quatro meses após a instalação}

ÁREA 1

Por se encontrar margeada por dois fragmentos florestais, a área 1 (antigo plantio de café), dentre as áreas de estudo, é a que mantém a umidade relativa do ar elevada por maior período do dia. Esta área também se destaca entre as demais por ser a mais protegida, uma vez que as áreas 2 (pastagem) e 3 (área com solo desnudo) estão localizadas relativamente próximas à rodovia Washington Luís.

As galharias, nesta área, apresentam sinal de decomposição (Fig. 15), observado pela presença de fungos decompositores de madeira. Nas demais áreas de estudo as galharias ainda não estão se decompondo; o que provavelmente se deve à maior umidade relativa do ar no local. A presença de aves visitando as galharias também é bastante notada, e as fezes destes animais são observadas, porém não foram observadas sementes nestas fezes.

Os poleiros artificiais estão sendo intensamente visitados por aves, como pode ser observado pela figura 16 . Ainda não houve a germinação de sementes de espécies florestais nativas, provavelmente trazidas por estes visitantes, mas a presença de fezes com sementes é bastante frequente sob os poleiros (Fig. 17C).

Frutos, sementes e fezes de animais exceto aves, também são observadas na área de estudos, fora de poleiros e galharias (Fig. 17 A-B; D-E), demonstrando que a área está sendo visitada por animais que podem estar dispersando diásporos e de alguma maneira contribuindo com o incremento da biodiversidade local. A presença frutos e sementes de "farinha seca" (Albizia hasslerii)caracteriza a ocorrência de dispersão anemocória. 
Figura 15.Galharias da área 1, ilustrando a presença de aves (A-B); $\quad$ Figura 17. Presença de sementes (A-C) e de fezes (D-E), na área 1,

fezes de aves (C-D); fungos (E-F) e insetos (G).
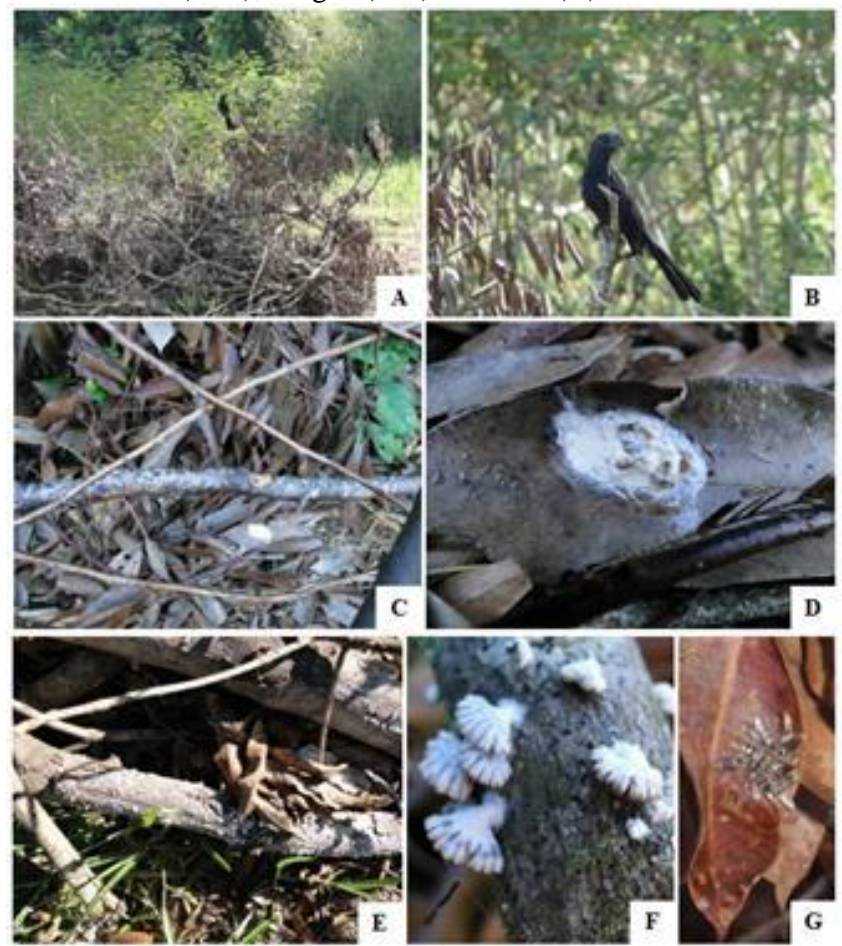

Figura 16. Presença de aves visitando a área 1.
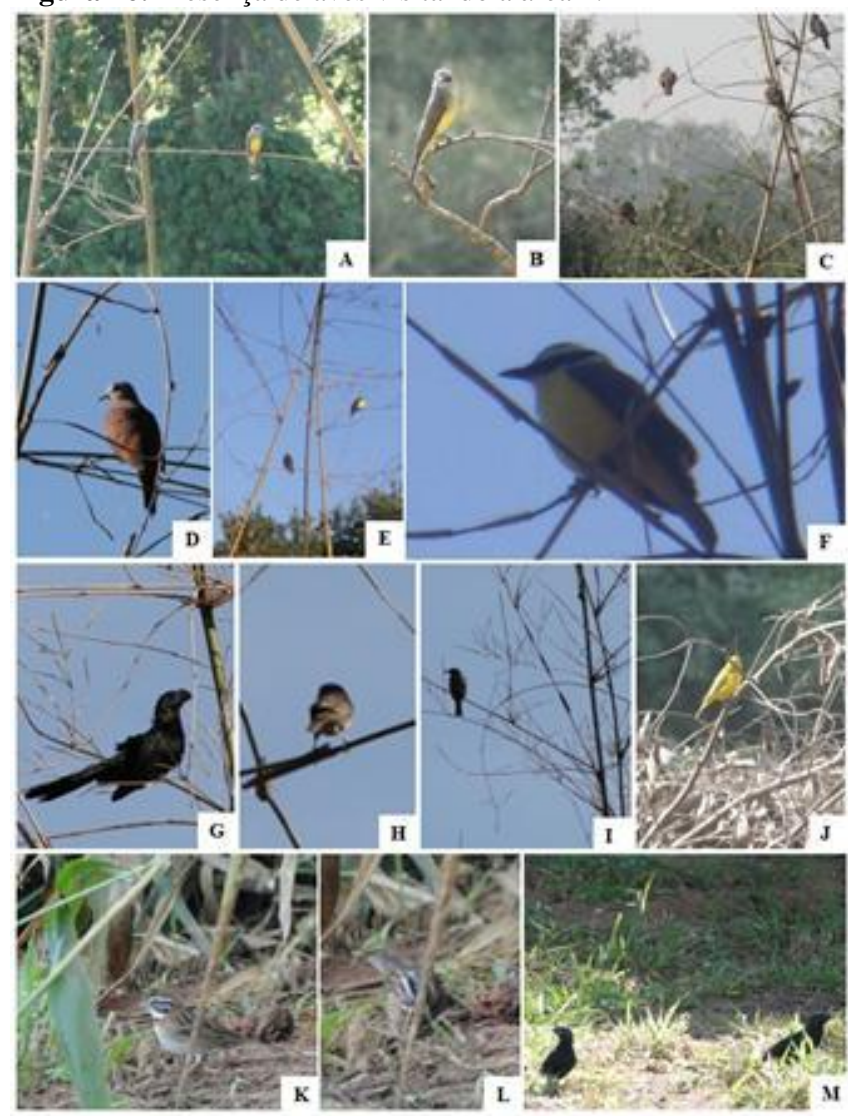

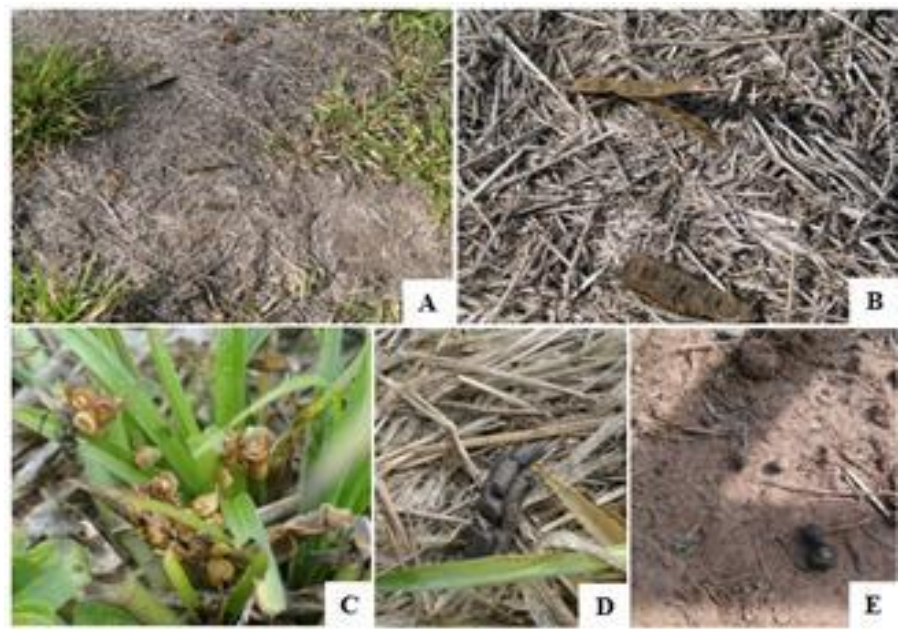

ÁREA 2

A visitação de aves na área 2 é pouco observada, acredita-se que seja pela poluição sonora bastante intensa, causada pela proximidade com a rodovia Washington Luis. Em observações periódicas tem sido notado que tanto na área estudada quando na borda da mata que margeia esta área, é pequena a presença de aves. Porém sob os poleiros foram encontradas fezes de aves com e sem a presença de sementes, como observado na figura 18 B-E. "Quero-quero" (Vanelluschilensis) é a única ave que tem presença constante neste local, porém esta espécie e também o anu branco (Guiraguira - também encontrado nesta área) possuem alimentação predominantemente animal, o que não é muito interessante para a técnica de nucleação, uma vez que não estão trazendo diásporos em suas fezes (mas não é descartada a dispersão através do corpo do animal).

Por se tratar de área de pastagem, foi realizado o arranquio da grama sob os poleiros (fig. $18 \mathrm{~F}$ ), visando facilitar a germinação das sementes que estiverem neste local.

As mudas de espécies florestais nativas estão sendo irrigadas periodicamente, porém ainda não atingiram tamanho suficiente para o sombreamento do local e posterior auxilio no incremento da biodiversidade (Fig. $18 \mathrm{~J}$ ); isto é observado para todos os locais estudados.

As galharias na área 2, ainda não demonstraram sinais de decomposição. Esta área é mais seca que as demais, e provavelmente ao início da estação chuvosa este sinais sejam observados. Houve uma discreta visitação de aves e outros animais nas galharias evidenciada pela presença de fezes, uma vez que a presença de animais neste local era rara.

No entorno das áreas 1 e 2 foi observada a presença de periquito de asa amarela (Brotogerisversicolorus - Fig. 19A), de tucanuçu (Ramphastos toco - Fig. 19B) e de udu de coroa azul (Momotusmomota- Fig. 19C), sendo esta última, espécies vulnerável a extinção. Estas aves se alimentam de diásporos, e por habitarem na mata próximo ás áreas de estudo 1 e 2 , são consideradas potenciais agentes incrementadores da biodiversidade destes locais. 
Figura 18. Área 2. $\mathrm{A}=$ vista geral; $\mathrm{B}-\mathrm{E}, \mathrm{G}=$ fezes de aves com a presença de sementes sob os poleiros; $\mathrm{F}=$ arranquio de grana sob poleiro; H - I = presença de "quero-quero" visitando a área; $\mathrm{J}=$ plantio de mudas em grupo de Anderson; $\mathrm{K}-\mathrm{M}=$ galharia (K-L anu branco e $\mathrm{M}$ - fezes de aves).
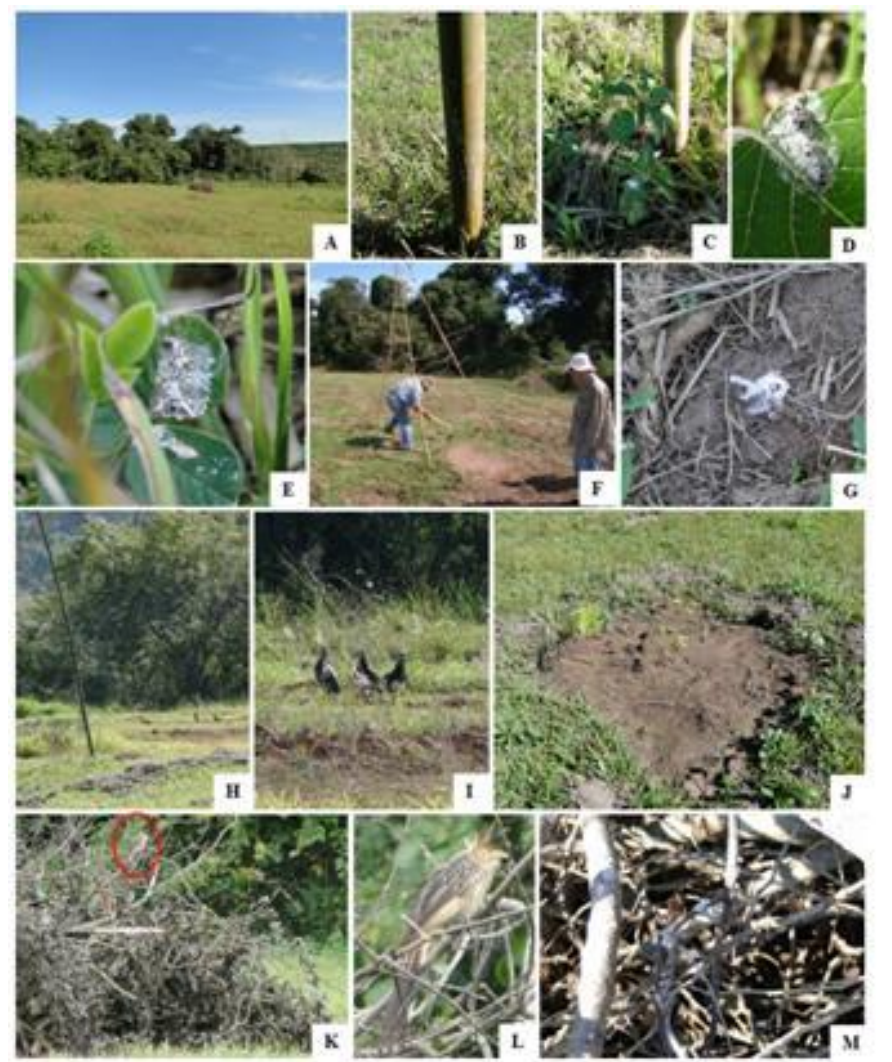

Figura 19. Aves encontradas no entorno das áreas de estudo 1 e 2: A $=$ periquito de asa amarela (Brotogerisversicolorus) $\mathrm{B}=$ tucanuçu (Ramphastos toco); $\mathrm{C}=\mathrm{udu}$ de coroa azul (Momotusmomota, espécies vulnerável à extinção).

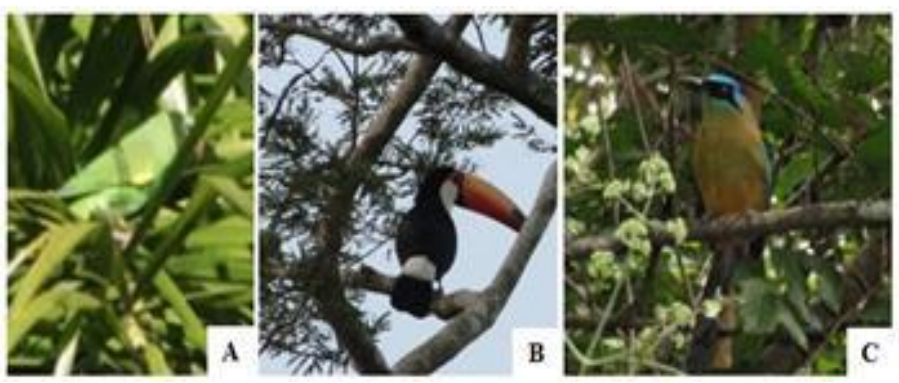

\section{ÁREA 3}

A visitação de animais na área 3 é bastante notada pela presença de fezes no local, seja de aves ou de outros animais (lebre, cotia e preá, observados até o momento) e de pegadas, como pode ser visto pela figura 20. Porém estes animais não tem o hábito de utilizar os poleiros e, quanto agalharia, somente foi constatada a presença de lebre utilizando- a como abrigo (Fig. $20 \mathrm{~J}-\mathrm{K}$ - presença de pegadas e de fezes de lebre sob galharia - nota: o animal foi visto, porém não fotografado).

No local de estudo, frequentemente são observados quero quero (Vanelluschilensis), pombo doméstico (Columbalivia) e seriema (Cariamacristata). Na mata que margeia este local, foram encontrados pica pau de topete vermelho (Campephilusmelanoleucos- Fig. 21B), pica pau (Fig. 21C - espécie ainda não identificada), saíra sete cores, periquito, bem te vi e gaviãozinho, sendo os quatro últimos observados, mas não documentados fotograficamente para a identificação ao nível de espécie.

Sementes de várias espécies foram encontradas sob o solo em toda a área 3 (Fig. 20), o que vem a ser um incremento a biodiversidade local. Provavelmente estas sementes vieram trazidas pelo vento, devido á suas características morfológicas e ao fato do local ter presença de ventos intensos.

A presença de animais e de sementes na área é um ótimo indício de que está havendo incremento da biodiversidade local, porém como se trata de uma área onde o solo foi retirado para uso em obras civis, o que restou está completamente compactado, não oferecendo condições favoráveis para a germinação de sementes. Contudo, esta pesquisa visa avaliar se as técnicas de nucleação podem ser recomendadas para este tipo de situação, e o princípio da nucleação é a recuperação da biodiversidade, sem a utilização de práticas agrícolas (como preparo de solo).

O sucesso da técnica testada depende de tempo para ser constatado, mas acredita-se que com o início das chuvas, muitos dados serão obtidos sobre a eficiência da técnica de nucleação neste e nos demais locais estudados, uma vez que os núcleos de biodiversidade (poleiros, galharias e mudas em grupo de Anderson) foram instalados no final da época das águas e o período de avaliação coincidiu com a época seca.

Figura 20. Presença de pegadas, de fezes de ave (seta vermelha), de fezes de outros animais (seta azul), e de sementes (seta verde), na área de estudo 3 .
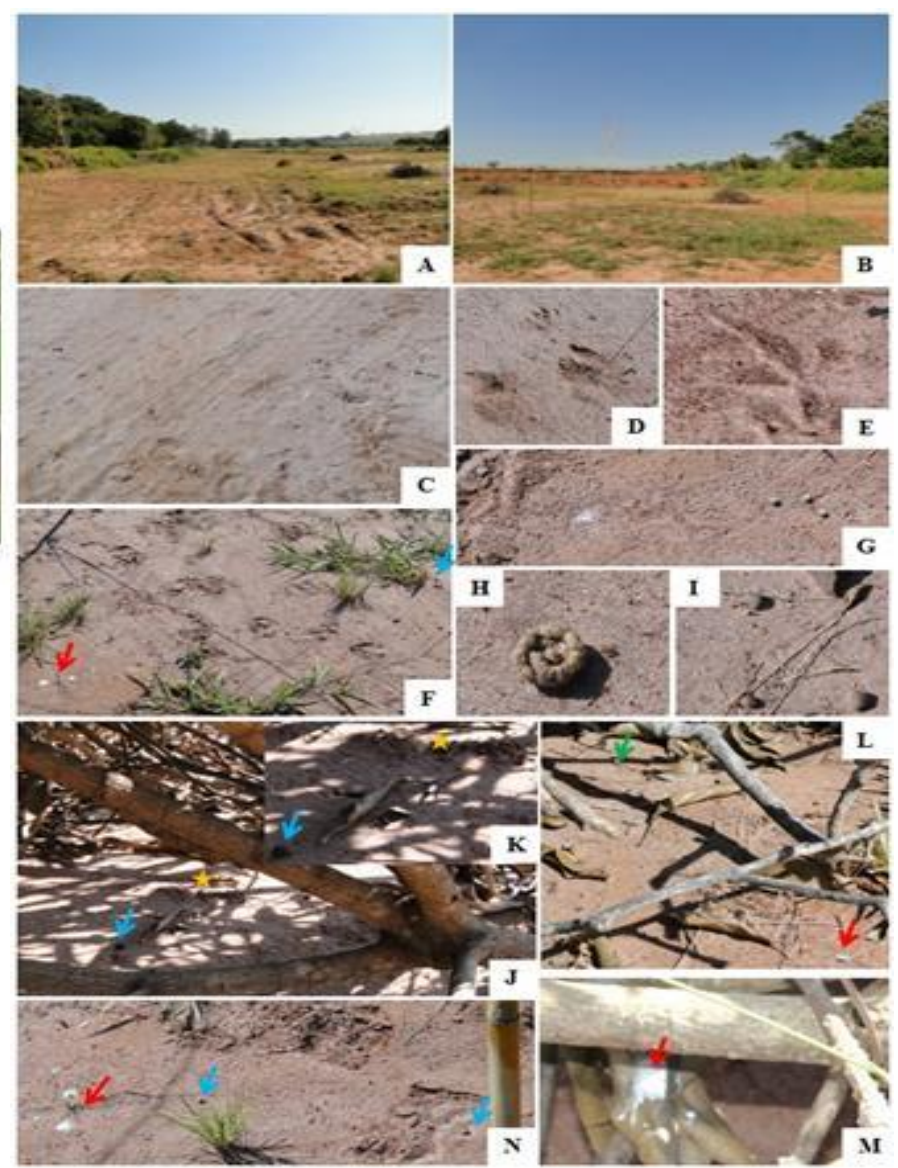
Figura 21. Aves encontradas na área 3.
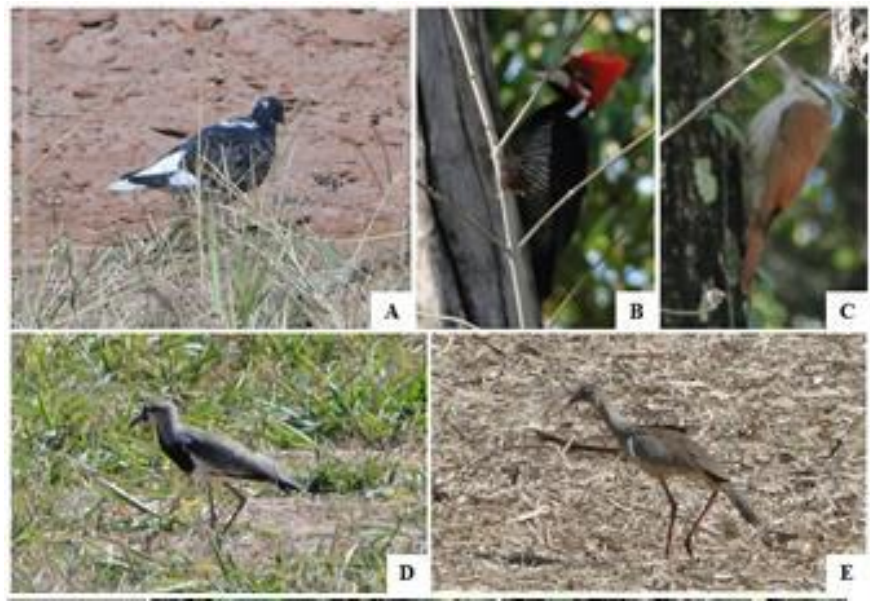

Avaliação quinze meses após a instalação dos núcleos

\section{ÁREA 1}

A área 1 apresenta grande mato-competição (Fig. 22), e após quinze meses da instalação dos núcleos no campo com pequeno incremento de espécies no local. As espécies no local, são ervas e arbustos, da família Solanaceae, considerados como planta daninha. Estas espécies habitam o entorno da área estudada, ocorrendo em campos com pastagem e com cultivo, e provavelmente suas sementes foram trazidas por aves.Devido a mato-competição acreditase que os diásporos trazidos pelos animais que frequentam os poleiros e as galharias, mesmo que tenham germinado não sobreviveram, por terem sido abafados pela presença do mato. Com relação às mudas provenientes do plantio em "Grupo de Anderson" e da chuva e banco de sementes, várias espécies não sofreram com a presença do mato; acredita-se que por terem sido levadas ao campo após estarem rustificadas (Fig. 22 D-E). Também foi observado que para as espécies secundárias e climáceas o mato teve um efeito benéfico (proporcionando sombreamento) e não tendo causado efeito de competição. Foi observada a presença de pegadas de felino na área de estudo (Fig. $22 \mathrm{C}$ ), provavelmente são de gato mourisco, o qual foi visto no local, por pessoas que circularam na área.

Figura 22. Área 1. A-B = vista geral; $\mathrm{C}=$ pegadas de felino; $\mathrm{D}-\mathrm{E}=$ mudas provenientes do banco/chuva de sementes adaptadas sem sofrer com mato-comneticão

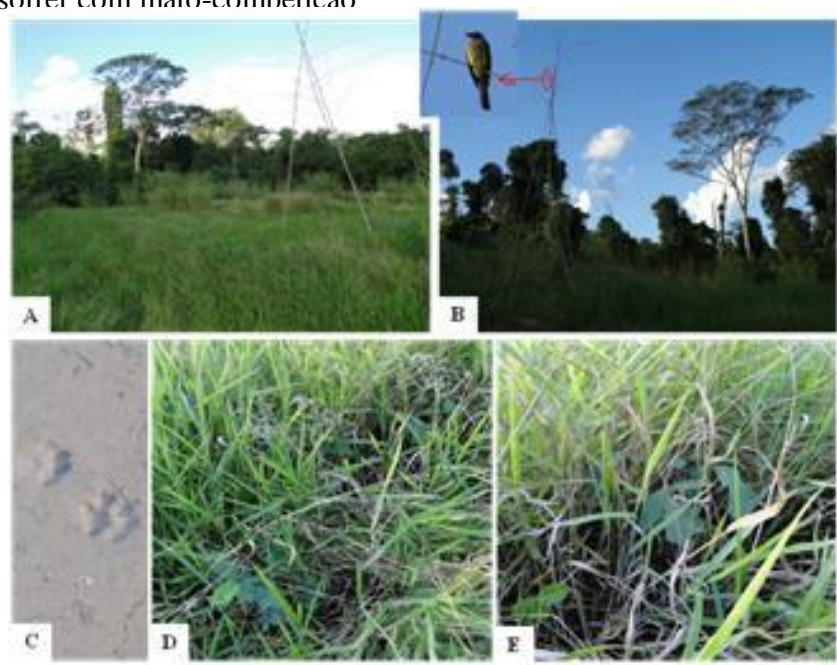

ÁREA 2

Das três áreas estudadas, a área 2 foi a que apresentou melhor resultado no período avaliado (Fig. 23). Por se uma área de pastagem, este local não sofreu a presença de mato-competição, como observado na área 1 . Com relação à visitação de animais no local, por ser raramente observada a presença destes, no início do estudo acreditou-se que devido à poluição sonora (pois esta área está localizada próximo a Rodovia Washington Luis) a presença de animais na área era pequena. Depois de 15 meses de observação, embora não tenham sido observados animais na área (salvo a presença de algumas aves), sabe-se que estes frequentam bastante o local. Isto pode ser constatado pelo grande incremento de espécies novas na área (Fig. 23B-E), provavelmente trazidas por estes animais. $O$ vento também contribuiu para o ganho de biodiversidade da área, pois algumas das espécies novas observadas possuem dispersão anemocórica.

Figura 23. Vista geral da área 2 mostrando a diversidade de espécies vegetais acrescentadas à área, trazidas por animais e/ou pelo vento.
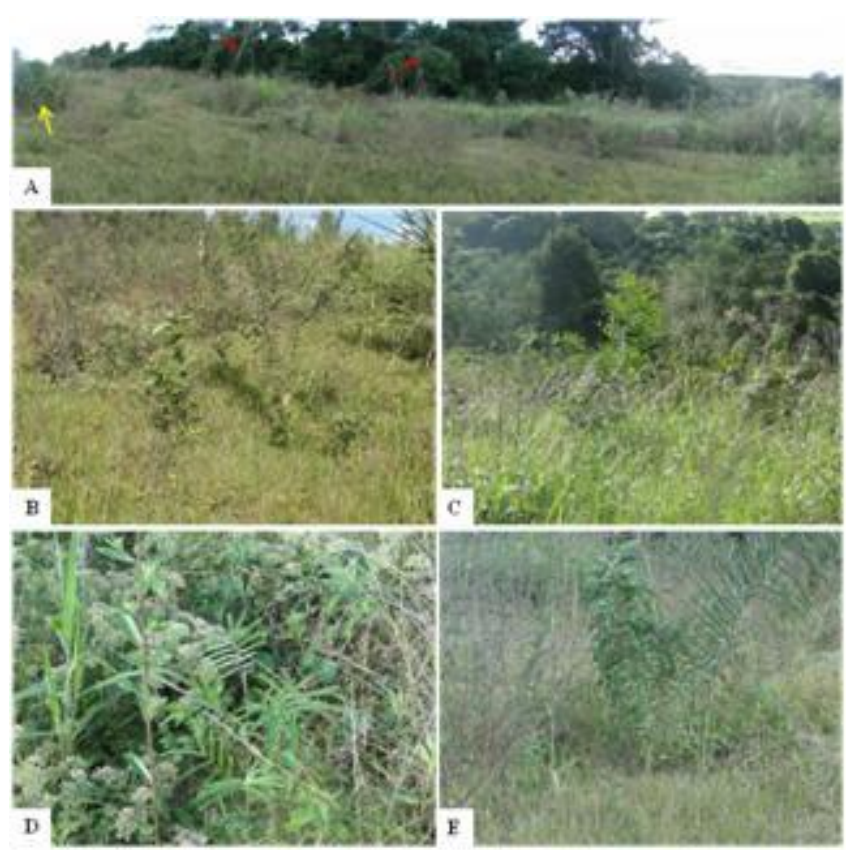

Figura 24. Detalhes da área 2, mostrando mudas provenientes de banco e chuva de sementes (levado ao campo com as mudas rustificadas), perfeitamente adaptadas ao local.

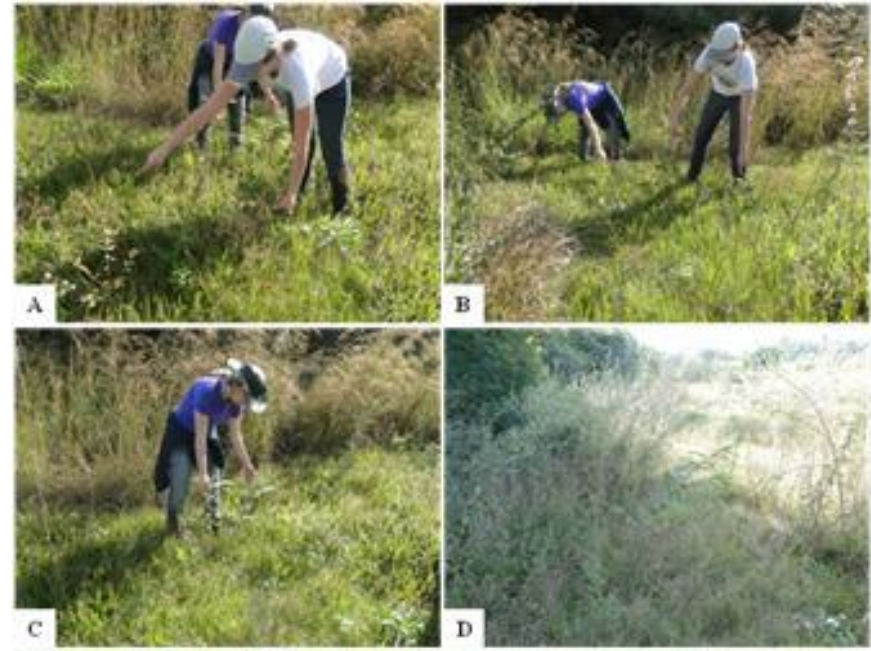


Com relação às mudas oriundas do banco de sementes do solo e da chuva de sementes, estas foram levadas ao campo após terem sido rustificadas no viveiro e se adaptaram perfeitamente ao local (Fig. 24).

As galharias se mostraram bastante eficientes para o incremento de espécies ao local, o que pode ser confirmado pela figura $25 \mathrm{~A}-\mathrm{C}$, onde se observa uma diversidade de espécies crescendo sobre e sob os galhos.

A presença de espécies tanto herbáceas ( juá) como arbóreas (goiabeira) demonstra que este núcleo foi visitado por animais, os quais se utilizaram da galharia seja para pouso (no caso de animais que depositaram diásporos sobre os galhos), seja para abrigo (no caso de animais que depositaram diásporos no solo, sob os galhos).

No caso dos poleiros artificiais, pode ser observado que a vegetação abaixo destes núcleos é composta por plantas herbáceas, as mesmas que dominam toda a área (Fig. 25 DE), não demonstrando intensa visitação por parte das aves. Em um, dos quatro poleiros instalados no local, foi observada a presença de plantas de goiabeira crescendo sob o poleiro (Fig. $25 \mathrm{~F}$ ); não se pode afirmar que estas plantas tinham sido trazidas por um animal que se utilizou do poleiro, pois também pode ter havido o transito de animais maiores sob este núcleo.

Figura 25. A-C $=$ galharias, mostrando o incremento de biodiversidade vegetal proveniente dos agentes dispersores (animais e vento) que agiram em decorrência da presença deste núcleo no local. $\mathrm{D}-\mathrm{F}=$ Poleiros artificiais; $\mathrm{D}-\mathrm{E}$ : vista geral; $\mathrm{F}=$ detalhe de goiabeiras crescendo sob poleiro. $($ seta vermelha $=$ poleiro).

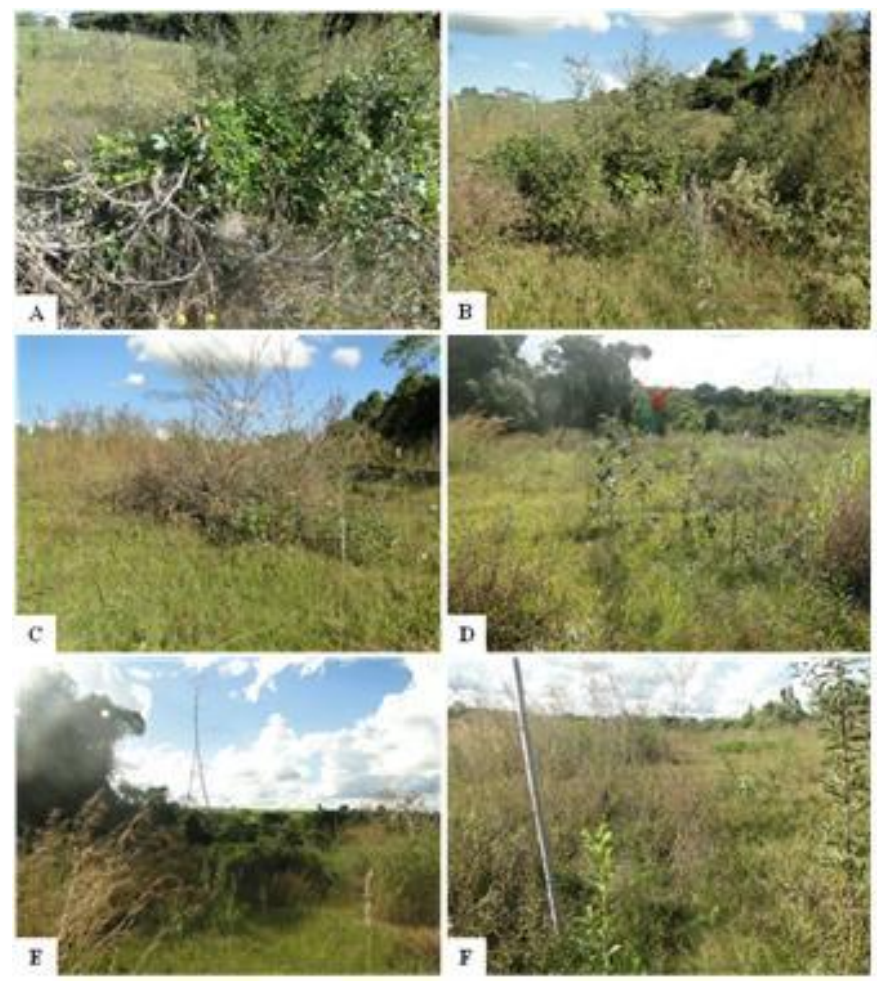

\section{ÁREA 3}

$\mathrm{O}$ incremento de espécies vegetais na área 3 foi pequeno (Fig. $26 \mathrm{~A}-\mathrm{D})$, isto se deve ao fato de que este local possui um fragmento de mata próximo, proveniente de reflorestamento, o qual se encontra em estado inicial de regeneração (portanto, com pouca diversidade de espécies para contribuir com o estudo em questão), além de apresentar solo extremamente compactado e pobre em nutrientes, onde os horizontes A e B foram retirados.

As espécies acrescidas ao local são consideradas daninhas (gramíneas e algumas dicitiledôneas), também foram observadas plantas de espécies da família Solanaceae (Fig. 26 B-C).Sob os poleiros somente observou-se fezes de animais (Fig. $26 \mathrm{E}$ ), porém não aparentando ter a presença de diásporos.

Com relação às mudas do "Grupo de Anderson", apenas o angico amarelo (Fig. 26 F) e o jacarandá mimoso (Fig. 26 G) sobreviveram.

Figura 26. Área 3. $\mathrm{A}=$ vista geral; $\mathrm{B}-\mathrm{C}=$ espécies no local por regeneração natural; $\mathrm{D}=$ poleiro artificial; $\mathrm{E}=$ fezes sob poleiro devido a visitação de animais; F-G = mudas do "Grupo de Anderson", adaptadas ao local

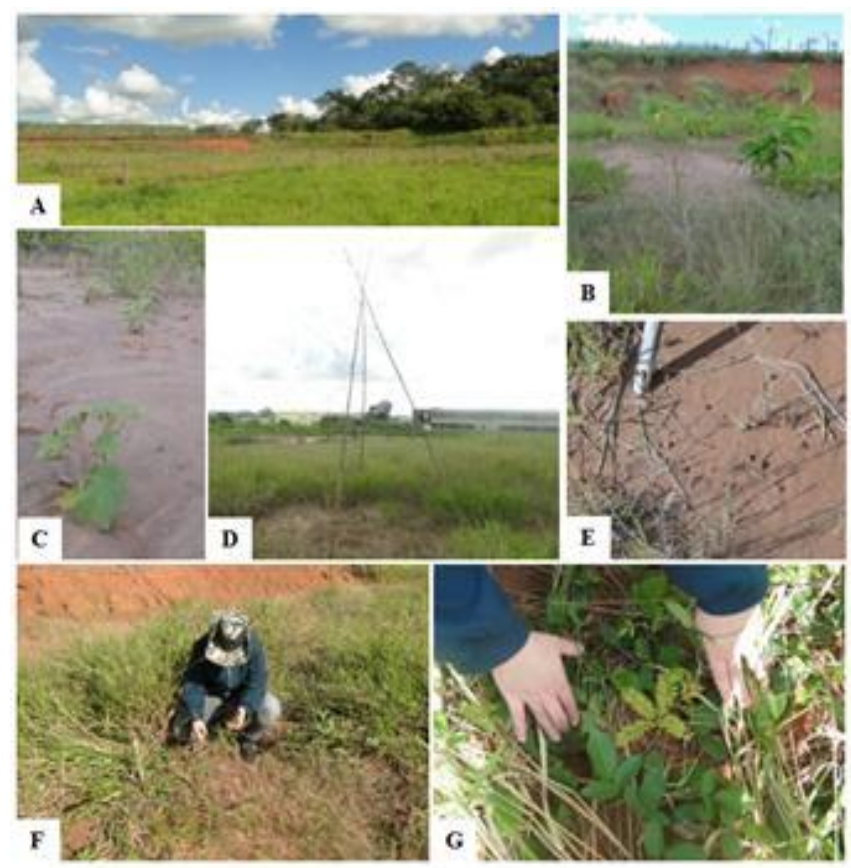

Ao observarmos as galharias (Fig. 27) notamos a presença de pegadas de animais em seu entorno e sob os galhos (Fig. 27 C-D), porém a presença de diásporos trazidos por estes animais não foi observada. Fungos decompositores de madeira foram registrados nas galharias (Fig. 27 E-F), mas sua decomposição, de maneira geral, está lenta.

Diante da visão geral observada na área 3, pode-se inferir que os animais que visitam este local não são bons dispersores, aparentemente porque não se alimentam de diásporos, uma vez que espécies frutíferas são pouco comuns na área e que estes animais não devem caminhar por outros fragmentos florestais para se alimentar. 
Figura 27. Galharias. A-B = vista geral; $\mathrm{C}-\mathrm{D}=$ pegadas de animais $($ amarelo $=$ felino e vermelho $=$ roedor $)$ no entorno da galharia $. \mathrm{E}-\mathrm{F}=$ presença de fungos decompositores de madeira, nas galharias.
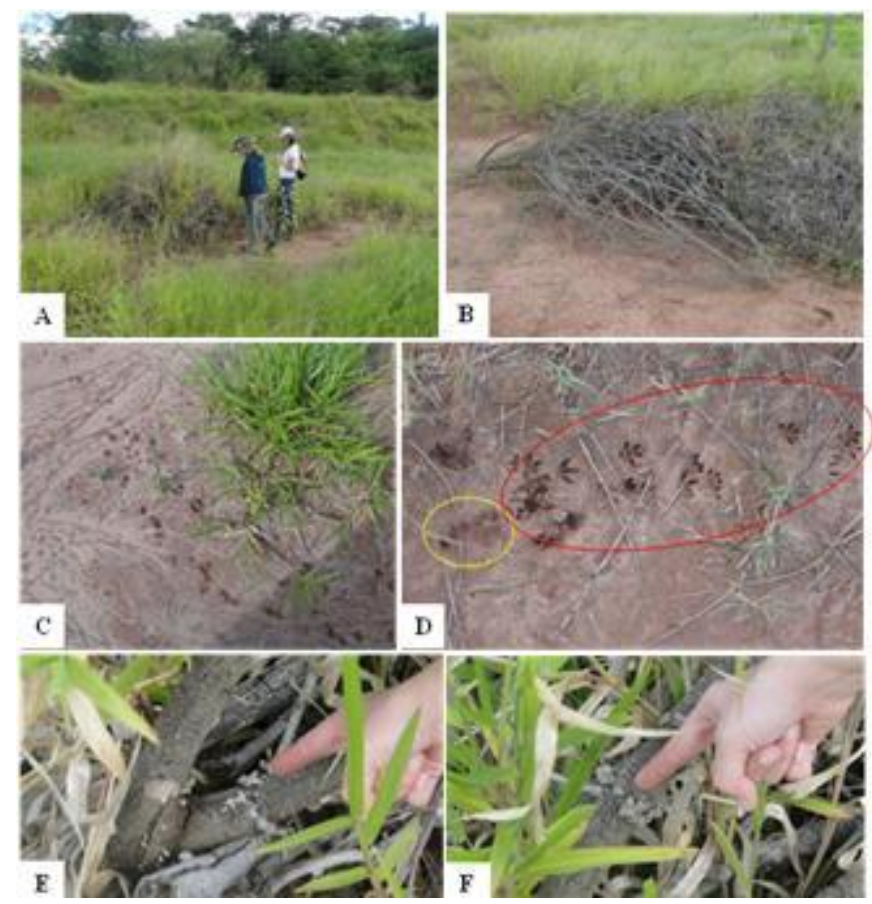

decorridos da instalação dos núcleos no campo, considera-se que:

Das situações de campo estudadas, a área de pastagem (área 2), por ter proximidade com fragmento florestal rico em diversidade e não apresentar contaminação pela presença de mato, se mostrou a situação de campo onde a técnica de nucleação apresentou melhor resultado.

Quando se tratar de local onde não há fragmento florestal próximo, ou o fragmento existente é pobre em diversidade de espécies, a técnica de nucleação torna-se limitada, uma vez que o incremento de biodiversidade no local será bastante lento. Este é o exemplo do ocorrido na área de estudo 3.

No caso de áreas contaminadas pela presença de mato (como ocorre na área 1), a técnica de nucleação também se torna limitada, pois apenas alguns núcleos terão resultados significativos, como o plantio de mudas em grupo de "Anderson" e chuva ou banco de sementes do solo germinados em viveiro e com as mudas transplantadas para o campo após estarem rustificadas. Poleiro artificial, galharia e banco ou chuva de sementes direto no solo, não são recomendados, pois devido a mato-competição, as plântulas germinadas serão abafadas e provavelmente não sobreviverão (salvo os casos de espécies secundárias ou climácicas, que por necessitarem de sombreamento na fase inicial de vida podem ser beneficiadas por este microclima).

Na figura 28, pode-se ter uma idéia de todos as pássaros que foram identificados nas áreas e no entorno .

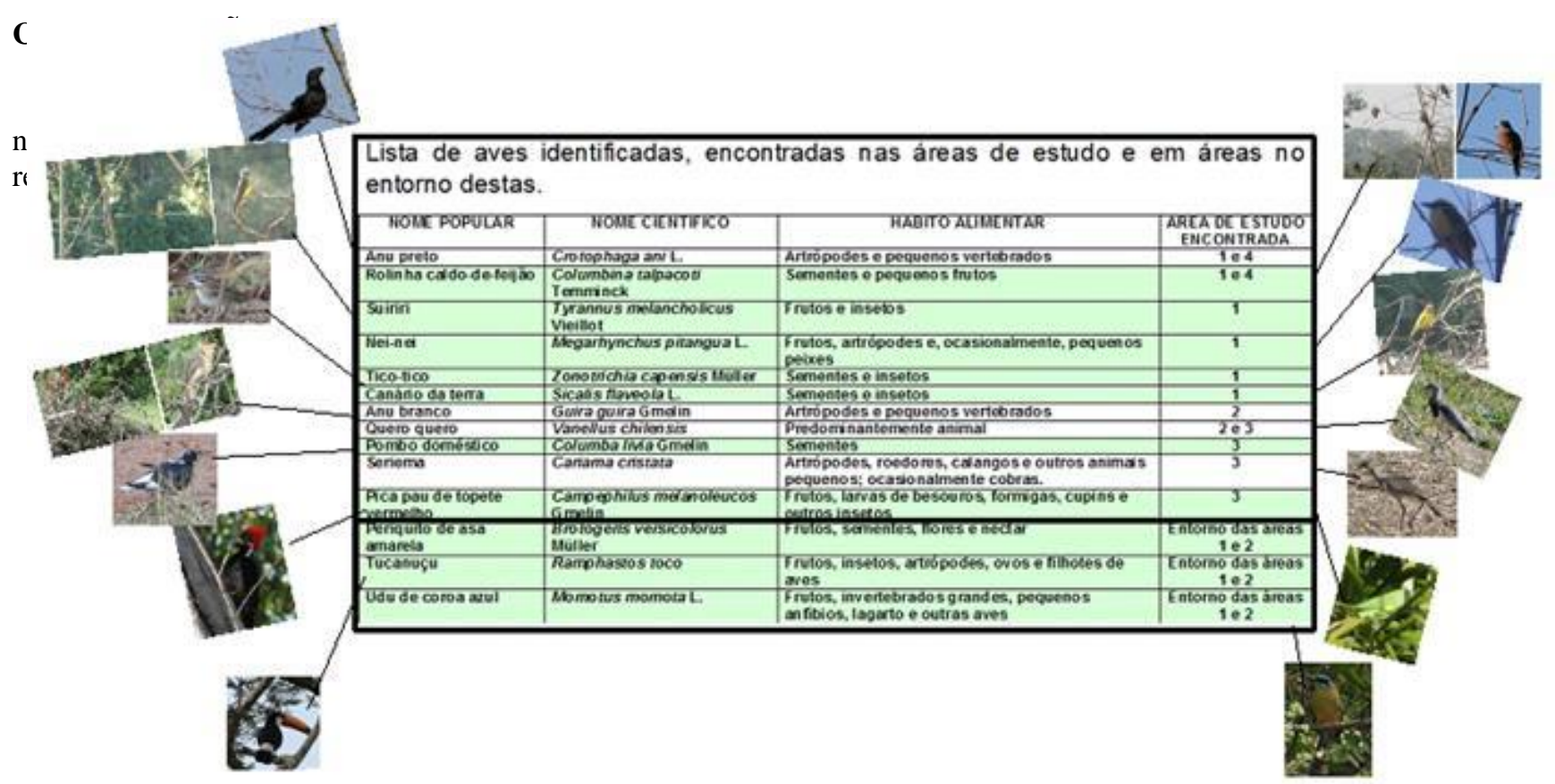

Figura 28. Lista de aves identificadas, encontradas nas áreas de estudo e em áreas no entorno destas. (Em destaque: espécies que se alimentam de diásporos).

\section{AGRADECIMENTOS}

Ao IMES Catanduva e ao Polo Centro Norte/ APTA que contribuíram para a realização do trabalho.

Ao Comitê da Bacia Hidrográfica dos Rios Turvo e Grande (CBHTG) e ao FEHIDRO e que financiaram o projeto ( Projeto FEHIDRO -TG 349/2009)

\section{REFERÊNCIAS BIBLIOGRÁFICAS}

BECHARA, F. C. Unidades Demonstrativas de Restauração Ecológica através de Técnicas Nucleadoras: Floresta Estacional Semidecidual, Cerrado e Restinga. Tese (Doutorado em Recursos 
Florestais - Conservação de Ecossistemas Florestais) Piracicaba, Universidade de São Paulo/Esalq. 2006. 248p.

REIS, A.; BECHARA, F. C.; ESPÍNDOLA, M. B. de; VIEIRA, N. K.; SOUZA. L. L. de. Restauração de áreas degradadas: a nucleação como base para incrementar os processos sucessionais. Natureza \& Conservação, Curitiba . vol 1 . n 1 . abril 2003 - pp. 28-36.

REIS, A.; ROGALSKI, J M.; BERKENBROCK, I. S.; BOURSCHEID, K. 2003 b. A nucleação aplicada à restauração ambiental. In: Anais Seminário Nacional Degradação e Recuperação Ambiental. Foz do Iguaçu.

REIS, A; TRES, D. R; BECHARA, F. C. A Nucleação como Novo Paradigma na Restauração Ecológica: "Espaço para o Imprevisível". Simpósio sobre Recuperação de Áreas Degradadas com Ênfase em Matas Ciliares. São Paulo, Instituto de Botânica. novembro de 2006. 16p. 